\title{
A GESTÃO DA INFORMAÇÃO NA BIBLIOTECA UNIVERSITÁRIA COMO FERRAMENTA AUXILIAR AO PLANEJAMENTO ESTRATÉGICO: UM EXEMPLO DE ANÁLISE DE IMPACTO
}

\author{
Managing information in the university library as an \\ auxiliary tool to strategic planning: an example of impact \\ analysis
}

\author{
Maurício Marques de Faria \\ Doutor em História das Ciências e das Técnicas e Epis- \\ temologia (UFRJ). Gerente de Análise de Inteligência \\ de Segurança Corporativa (Petrobras). Pesquisador \\ Colaborador no Laboratório de Simulações e Cenários \\ (Escola de Guerra Naval).
}

\section{Margareth Monteiro Gadelha}

Mestre em Memória Social pela (Unirio). Bibliotecária Documentalista (UFRJ).

RESUMO: Partindo do pressuposto que a informação científica é um produto econômico, esse trabalho propõe, a partir de técnicas de gestão da informação, e em especial a ferramenta de análise de impacto, averiguar de forma empírica a produção do conhecimento científico e tecnológico e as redes de relacionamento entre uma biblioteca universitária e um departamento de pesquisa externo. O gerenciamento em instituições sem fins lucrativos como uma biblioteca universitária exige uma percepção do ambiente que a circunda, integrada ao planejamento da instituição maior, sem perda de foco na sua atividade fim, para obtenção de quadro em perspectiva dos rumos de longo prazo a serem definidos. Neste cenário, o conhecimento torna-se o grande diferencial competitivo, surgindo como fator de produção mais importante na economia da informação, pois numa sociedade em que informação, conhecimento e inovação são primordiais, gerir informação é uma das grandes preocupações e desafios da ciência da informação. A análise de impacto pode ser utilizada como ferramenta auxiliar na elaboração de políticas baseadas em performance, e os dados obtidos podem ajudar os planejadores a identificar lacunas de conteúdo informacional, parcerias que devem ser incrementadas ou estimuladas e a necessidade de criação de novos serviços para atender às necessidades de conhecimento dos usuários.

PALAVRAS-CHAVE: Análise de impacto. Planejamento estratégico. Biblioteca universitária. Gestão da informação.

ABSTRACT: Assuming that scientific information is an economic product, this work 
proposes, using information management techniques, and in particular the impact analysis tool, investigate empirically the production of scientific and technological knowledge and networks of relationships between a university library and a research department. The management in nonprofit institutions as a university library requires a perception of the surrounding environment, integrated into the planning of the larger institution, without losing focus on its activity in order to obtain a picture in view of the direction of long term still to be defined. In this scenario, the knowledge becomes a great competitive advantage, emerging as the most important factor of production in the information economy, because in a society where information, knowledge and innovation are paramount, managing information is one of the major concerns and challenges of information science. The impact analysis can be used as a tool to assist in the development of policies based on performance, and the data obtained can help planners identify gaps of informational content, partnerships that should be enhanced or stimulated and the need of creating new services to meet the user's knowledge needs.

KEYWORDS: Impact Analysis. Strategic Plannig. University Library. Information Management.

\section{Introdução}

A proposta desse trabalho é apresentar possibilidades de cooperação entre biblioteca universitária e institutos de pesquisas a partir da elaboração de um planejamento estratégico baseado na gestão da informação, apresentando como exemplo o uso de ferramenta a análise de impacto das parcerias entre universidade e empresa na produção do conhecimento científico e tecnológico, tendo como instrumento de pesquisa as bases de dados disponíveis nas bibliotecas da Universidade Federal do Rio de Janeiro (UFRJ).

A economia globalizada requer contínua análise sobre os fatores de sucesso para o desenvolvimento de novos instrumentos e processos que permitam ao sistema de Ciência e Tecnologia (C\&T) o avanço do conhecimento e da inovação. Cada vez mais, é da ciência que esperamos respostas e do avanço da tecnologia que esperamos soluções. Entretanto, num mundo marcado por desigualdades, os esforços para desenvolver conhecimentos e gerar inovações se concentram em poucos países, considerados desenvolvidos, aumentando continuamente a distância entre os estes e os considerados "emergentes", categoria na qual se inclui o Brasil (BRASIL, 2008, p. 7).

Desta forma, como brasileiros, cabe-nos perguntar como diminuir essa distância que põe em jogo a riqueza de uma nação e também sua dignidade e liberdade. Dentro dessa perspectiva a educação e o desenvolvimento científico despontam como fatores de suma importância, e que necessitam de apoio e ações do Estado e da participação da sociedade, através de suas instituições educacionais e empresariais, entre outras, para o atingimento de um novo patamar de desenvolvimento, que reduza as desigualdades internas e externas do país. 
Nesse contexto, empresas intensivas em tecnologia ou que enfrentam uma concorrência globalizada deparam-se frequentemente com a necessidade de escolher um caminho que leve ao desenvolvimento tecnológico como fonte de vantagem competitiva. Dentre as opções existentes, a cooperação seria uma forma de acesso à tecnologia e à inovação. Comumente a cooperação é resultante de ações conjuntas de diferentes atores: no caso, empresa, universidade e governo, em modelos de arranjo interinstitucionais de natureza distinta, com finalidades diferentes e formatos bastante diversos. As universidades foram pressionadas pelos governos a estabelecerem vínculos mais fortes com as empresas, buscando fontes alternativas de financiamento, num movimento que se caracterizou pela intensificação da transferência de tecnologia das universidades para a empresa e a comercialização do trabalho acadêmico.

Como lembra o ex-reitor da Universidade de São Paulo (USP) entre 1997 e 2001, Prof. Marcovitch (apud PRADO, 2000, p. 5), "a universidade e a empresa são regidas por valores absolutamente próprios e distintos. São diferentes os seus ciclos de tempo, os seus objetivos e as suas motivações. No entanto, é necessário que haja complementaridade entre elas, em proveito do todo social".

Esta atuação conjunta não pode simplesmente erradicar a autonomia institucional da universidade em troca de um financiamento diretivo, pois ela desempenha um papel democratizante, ser um bem público para melhorar a sociedade na qual está inserida. Cabe, portanto, buscar um adequado balanceamento entre as demandas próprias, sociais e empresariais às quais a universidade está sujeita.

É nesse contexto que entender a produção e o resultado das parcerias firmadas entre universidade e empresa é fundamental para o planejamento dos institutos de pesquisa. Uma forma de obter esse conhecimento, gerado na própria instituição, é utilizar as técnicas de gestão da informação, para melhorar o fluxo de informações e resgatar o conhecimento produzido pela instituição de forma a subsidiar o processo de tomada de decisão, através da análise consolidada dos resultados, da análise de impacto das parcerias entre universidade e empresa na produção do conhecimento científico e tecnológico.

Considerando o pressuposto que informação científica é um produto econômico, como atestam Kannebley e Carolo (2013), este trabalho propõe, a partir de técnicas de gestão da informação, averiguar de forma empírica a produção do conhecimento e as redes de relacionamentos estabelecidas entre a Petrobras e a UFRJ.

Os produtos econômicos da pesquisa universitária seriam a informação científica e tecnológica, equipamentos e instrumentação, capital humano qualificado, redes de capacitações científicas e tecnológicas, além de protótipos para novos produtos e processos. (KANNEBLEY; CAROLO, 2013, p. 87). 
Sua justificativa repousa na hipótese de que a identidade da Petrobras fortalece o desenvolvimento da pesquisa na Universidade, no sentido que pesquisadores e alunos buscam estudá-la, mesmo não havendo uma participação efetiva da empresa em determinadas pesquisas, uma vez que em muitos trabalhos a mesma desponta como objeto de estudo em diversas áreas. Para a maioria dos cidadãos brasileiros a identidade da Petrobras marcou a memória como sendo a empresa dos brasileiros, provavelmente devido à consagração do lema "o petróleo é nosso". Embora os escândalos de corrupção que surgiram após 2013 tenham corroído profundamente esta imagem, no meio científico a empresa ainda desponta como referência tecnológica e em pesquisa científica. Para Carlos Vogt, linguista, e professor titular na área de semântica argumentativa da Universidade de Campinas (UNICAMP), o petróleo mobiliza a sociedade brasileira desde o século XX, diz Vogt (2010)

O petróleo sempre mobilizou politicamente a sociedade brasileira ao longo do século XX e assim continua a fazê-lo nesse começo de século, por muitas razões, entre elas a de seu alto valor estratégico para a economia dos países e para o desenvolvimento das nações. (VOGT, 2010, p. 1).

Vogt (2010) lembra também a força que a campanha “o petróleo é nosso" exerce nos brasileiros desde 1947, quando fala:

Desde 1947 a opinião pública brasileira foi confrontada com essa duplicidade de atitudes, intensificada pela campanha "o petróleo é nosso", que alguns chegam a considerar tão intensa e apaixonante, no século XX, quanto fora a da abolição da escravatura, no século XIX. (VOGT, 2010, p. 1).

A análise de impacto funciona como um indicador bibliométrico, calculado com base na produção científica, em nosso caso de temas envolvendo Petrobras e UFRJ. Ela identifica de maneira mais precisa o relacionamento entre documentos que tratam do mesmo assunto e, por conseguinte, da rede de relacionamento entre autores, instituições e sua produção (MUGNAINI; STREHL, 2008). Pode, portanto, ser utilizada como ferramenta auxiliar na elaboração de políticas baseadas em performance. A influência de um corpo de publicações sobre outro e o mapeamento das ligações estabelecidas entre as áreas científicas, permite analisar o valor de uma investigação científica em particular e ajudar a biblioteca universitária a direcionar seus serviços, identificando a adequação de seu conteúdo informacional bem como a densidade de seu acervo e sua obsolescência, de forma a contribuir para o fortalecimento das pesquisas de interesse específico da universidade.

\section{Planejamento estratégico}

O gerenciamento em instituições sem fins lucrativos como uma biblioteca universitária, que tem como finalidade subsidiar as atividades de ensino pesquisa e 
extensão com informação, exige uma percepção do ambiente que a circunda integrada ao planejamento da instituição maior, sem perda de foco na sua atividade fim (MAIA; OLIVEIRA, 2008).

Apesar de não visar ao lucro econômico, as bibliotecas gerenciam verbas da própria instituição e recebidas de agências financiadoras para projetos de compra de livros, infraestrutura física, mobiliário, conservação, restauração, entre outras necessidades (DI FOGGI; COLETTA; CRISTIANINI, 2010).

O planejamento estratégico é um processo lógico e analítico de escolha de uma posição futura da empresa em face do ambiente. Por ser um processo complexo e com potencial de perturbação organizacional, necessita critério e cuidado em sua implantação, pois caso contrário, as resistências internas podem inviabilizar sua implantação (ANSOFF; MCDONNELL, 1993).

Ele inclui um caráter analítico de seu ambiente interno, por meio do diagnóstico situacional da biblioteca, com identificação de seus pontos fortes e fracos, além da visão prospectiva de definição da perspectiva de futuro e dos objetivos a atingir, com estratégias de curto, médio e longo prazos, monitorados, mensurados e desafiadores, mas passíveis de serem atingidos com os recursos disponíveis (MAIA; OLIVEIRA, 2008).

Assim, é preciso identificar os propósitos básicos da organização, no caso, a biblioteca universitária, bem como analisar suas forças e fraquezas, suas oportunidades e ameaças, permitindo a definição de objetivos e indicadores para a construção de diretrizes estratégicas que forneçam soluções para as questões levantadas durante o processo, ao mesmo tempo em que possibilita uma visão comum e o comprometimento de todos os envolvidos com a missão da organização (AMARAL et al. 2009). Essa visão fornece um quadro em perspectiva "do que somos, o que fazemos e para onde vamos", indicando um rumo de longo prazo.

Já a missão explicita o "negócio" indicando a razão de existir e delineando a identidade da organização. A missão de qualquer biblioteca deve se coadunar com os interesses da instituição à qual pertence (MAIA; OLIVEIRA, 2008), o que não impede a inserção da criatividade para gerar mudanças que atuem na "reformulação" das organizações. Com esses elementos a estratégia mostra o caminho, o objetivo e aonde se quer chegar (DI FOGGI; COLETTA; CRISTIANINI, 2010).

Se as bibliotecas e unidades de informação querem cumprir sua missão, precisam adaptar as tecnologias às necessidades e quantidade de informação que dispõe. Num ambiente de incertezas crescentes os bibliotecários necessitam cada vez mais de um preparo administrativo e gerencial (AMARAL et al. 2009).

A estratégia integra, em um todo coerente, as principais metas, políticas e ações de uma organização. Para Mintzberg e Quinn (2001, p. 20):

Uma estratégia bem formulada ajuda a ordenar e alocar os recursos de uma organização para uma postura singular e viável, com base em suas competências e deficiências internas relativas, mudanças no ambiente antecipadas e providências contingentes realizadas por oponentes inteligentes. 
É preciso se antecipar às mudanças e buscar uma postura pró-ativa frente às forças atuantes no ambiente (DI FOGGI; COLETTA; CRISTIANINI, 2010). A estratégia não se encerra na elaboração do plano, é preciso constantemente avaliar sua implantação e, se necessário, revê-la.

Portanto, ao se obter uma maior qualidade dos serviços prestados, se viabiliza "uma melhor qualidade de pesquisa e do ensino nas universidades, pois a biblioteca funciona como um instrumento de apoio a essas atividades. Aliado a isso, está a produção científica das universidades, que tem nas bibliotecas uma fonte inesgotável de recursos de informação e conhecimento, nos mais variados suportes e formas de acesso" (DI FOGGI; COLETTA; CRISTIANINI, 2010, p. 2).

\section{Gestão da informação}

Shiyali Ramamrita Ranganathan defendia, ainda na década de 1930, que todo bibliotecário, mas principalmente os que eram administradores das bibliotecas, tinham a reponsabilidade de pensar incisivamente sobre melhorias nos serviços de biblioteca, implementando novos serviços e aumentando a performance dos profissionais. Suas cinco leis: os livros são para usar, a cada leitor seu livro, a cada livro seu leitor, poupe o tempo do leitor e a biblioteca é um organismo em crescimento, traduzem essa ideia com agilidade e flexibilidade e, ainda hoje, são plenamente válidas e atuais, bastando simplesmente pensarmos em modernizar seus termos, vendo em livros, informação; em leitor, usuário; e em biblioteca, sistemas de informação, de forma a identificarmos as atribuições dos modernos serviços de informação ou bibliotecas (COCHRANE, 1992).

Os desafios presentes na sociedade, no séc. XXI, transformam o conhecimento no grande diferencial competitivo das instituições, como o único elemento capaz de reduzir a incerteza e permitir a tomada de decisões de forma ágil e flexível. Assim, o conhecimento surge como o fator de produção mais importante na economia da informação (LONGO, 2014).

A superprodução de informação e a existência de sofisticados sistemas de recuperação e gestão da informação exigem conceitos e procedimentos práticos para o estabelecimento de estratégias e a elaboração de planos de trabalho que busquem as oportunidades para maximizar a eficiência da organização (AMARAL et al. 2009).

$\mathrm{Na}$ Sociedade da Informação, o fenômeno informação assume grandes dimensões e, com a globalização, o avanço tecnológico e o crescente fluxo de formação, a forma de acompanhamento e absorção desse volume informacional tem sido muito discutido (DELAIA; FREIRE, 2010).

Molda-se, então, um novo cenário econômico, exigindo investimentos em monitoramento sistêmico das informações e incentivo à geração de novos conhecimentos, de modo a possibilitar que as instituições se antecipem as dificuldades, identificando novas oportunidades e subsidiando decisões estratégicas (PEREIRA; CIANCONI, 2008).

A Gestão da Informação trata da teoria e da prática que envolve a criação, identificação, coleta, validação, representação e uso da informação, e sua relação com 
os processos administrativos e tecnologias envolvidas, enfocando o indivíduo e suas "situações-problemas" no contexto dos fluxos de informação (DELAIA; FREIRE, 2010, p. 112).

Ela trabalha no âmbito do conhecimento explícito e consiste nas atividades de planejar, elaborar normas e modelos, selecionar, organizar, coordenar, controlar, processar, comunicar, disseminar e avaliar informações formais e informais. Envolve o monitoramento de informações em todo o seu ciclo e a sistematização e coordenação de esforços para regular e facilitar a aquisição, o processamento, o armazenamento, a disseminação e o acesso à informação, visando fazer com que as informações apoiem com efetividade as operações da organização, racionalizando os fluxos (PEREIRA; CIANCONI, 2008).

Em uma sociedade em que informação, conhecimento, criatividade e inovação são primordiais, "gerir informação" é uma das grandes preocupações e desafios da ciência da informação (DELAIA; FREIRE, 2010, p. 111). Portanto, entendemos que o estudo do uso de fontes de informação e do processo de produção científica apresentam resultados que servem como subsídios para uma política de Gestão da Informação (DELAIA; FREIRE, 2010.).

\section{$4 \quad$ Parceria entre UFRJ e Petrobras}

Os primeiros Fundos Setoriais de C\&T foram criados em 1999, como instrumentos de financiamentos de projetos de pesquisa, desenvolvimento e inovação no País. De acordo com dados da Financiadora de Estudos e Projetos (FINEP), existem 16 Fundos Setoriais, sendo um destinado a promover a cooperação universidade-empresa, chamado Fundo Verde-Amarelo. As receitas dos Fundos são provenientes de contribuições incidentes sobre a exploração de recursos naturais pertencentes à União, parcelas do Imposto sobre Produtos Industrializados (IPI), e Contribuição de Intervenção no Domínio Econômico (CIDE), incidente sobre os valores que remuneram o uso ou aquisição de conhecimentos tecnológicos ou transferência de tecnologia do exterior. Estes Fundos são administrados pela FINEP, com exceção apenas ao Fundo para o Desenvolvimento Tecnológico das Telecomunicações (FUNTTEL), cuja gestão está a cargo do Ministério das Comunicações. O modelo de gestão dos fundos setoriais é baseado em Comitês Gestores, composto por representantes do Ministério da Ciência, Tecnologia e Inovação (MCTI), agências reguladoras, setores acadêmicos e empresariais, Finep e Conselho Nacional de Desenvolvimento Científico e Tecnológico (CNPq). Entre os fundos criados estão: da Energia, dos Recursos Hídricos, dos Transportes, dos Recursos Minerais, além do Programa de Estímulo à Interação universidade-empresa para o Apoio à Inovação e o Programa de Desenvolvimento Científico e Tecnológico do Setor Espacial.

Em 1997 foi promulgada a Lei n9.478/1997, conhecida como Lei do Petróleo. Esta Lei deu início a um novo modelo institucional no setor, com a quebra do monopólio exercido pela Petrobras na exploração, produção e refino de petróleo derivados e gás natural, e a criação da agência reguladora Agência Nacional de Petróleo (ANP). Em torno destas mudanças foi criado em 1999 o Plano Nacional de Ciência e Tecnologia 
do Setor de Petróleo, Gás Natural e Biocombustíveis (CTPETRO), fundo setorial do petróleo e gás natural.

O CTPETRO recolhe uma parcela dos royalties da produção de petróleo e gás natural, com o objetivo de financiar programas de amparo à pesquisa científica, ao desenvolvimento tecnológico do setor petrolífero e à formação de recursos humanos. Os recursos disponibilizados pelo CTPETRO visam investir em universidades e centros de pesquisa habilitados a desenvolver projetos ligados ao setor de petróleo e gás natural.

O Centro de Pesquisas e Desenvolvimento Leopoldo Américo Miguez de Mello (CENPES), criado nos anos 1960, está situado no campus da Cidade Universitária, na Ilha do Fundão, RJ, e após a inauguração das novas instalações, em 2010, passou a ocupar mais de 300 mil metros quadrados. No discurso de inauguração das novas instalações, o então Presidente Luiz Inácio da Silva, declarou que o valor de mercado da Petrobras, que era de US $\$ 15$ bilhões em 2003, havia passado para US $\$ 220$ bilhões, naquele momento. A ampliação do CENPES refletia esse crescimento e foi um referencial do aumento das atividades de Pesquisa e Desenvolvimento (P\&D) da empresa, que entrou em áreas como biocombustíveis e biotecnologia, além dos novos desafios pela exploração do petróleo na camada de pré-sal.

Em 2012, a Petrobras e a UFRJ inauguraram, o Núcleo de Biocombustíveis, de Petróleo e de seus Derivados (NBPD), também na Cidade Universitária. O complexo de laboratórios visa desenvolver pesquisas nas áreas de biotecnologia e de engenharia química. São estudadas linhas de pesquisa voltadas para o desenvolvimento de processos químicos e bioquímicos, com base em matéria-prima renovável, para obtenção de biocombustíveis, e estudos avançados com petróleo e seus derivados. Na inauguração do Núcleo, o gerente de Gestão Tecnológica da Petrobras Biocombustível, João Norberto Noschang Neto, lembrou que o projeto de produção do etanol de segunda geração, produzido a partir do bagaço de cana, começou na UFRJ há oito anos, e afirmou que a Companhia quer ter uma relação cada vez mais próxima da comunidade científica. (PETROBRAS, 2012).

\section{$5 \quad$ Metodologia}

Para obtenção dos dados da pesquisa foram utilizados os recursos das bases de dados Scopus e INPI, disponibilizadas no Portal Capes de Periódicos, e a Base de Dados Bibliográficos Minerva, da UFRJ. A delimitação do corpus pautou-se, inicialmente, pela possibilidade de estabelecer um panorama da produção acadêmica e científica, em uma rede de relacionamento que envolve o CENPES e a UFRJ. Como recorte temporal utilizamos o período entre 1955 (primeiro registro encontrado, no INPI) e 2013, de forma a cobrir a criação, desenvolvimento, maturação e pico de produção (2007-2012) da parceria.

\subsection{Base Scopus}

Na base Scopus, para estabelecer as categorias de análise, os parâmetros da pesquisa foram: Affiliation Petrobras. Com este procedimento os dados recuperados, no dia $11 \mathrm{de}$ 
julho de 2013, foram 2749 documentos no período de 1957- 2013, período foi recuperado pela base em função das datas dos documentos obtidos, dividindo-se entre: Paper, Artigo, Resenha, Resumo, Artigo na imprensa, Editorial, Errata, Livros, Indefinidos e outros. A partir deste resultado foi selecionada a opção Analyse results, e em seguida Affiliation name (Quadro 1), e o resultado foi a UFRJ como a instituição com maior índice de produção científica em parceria com a Petrobras, dos 2749 documentos 822 são em parceria com a universidade.

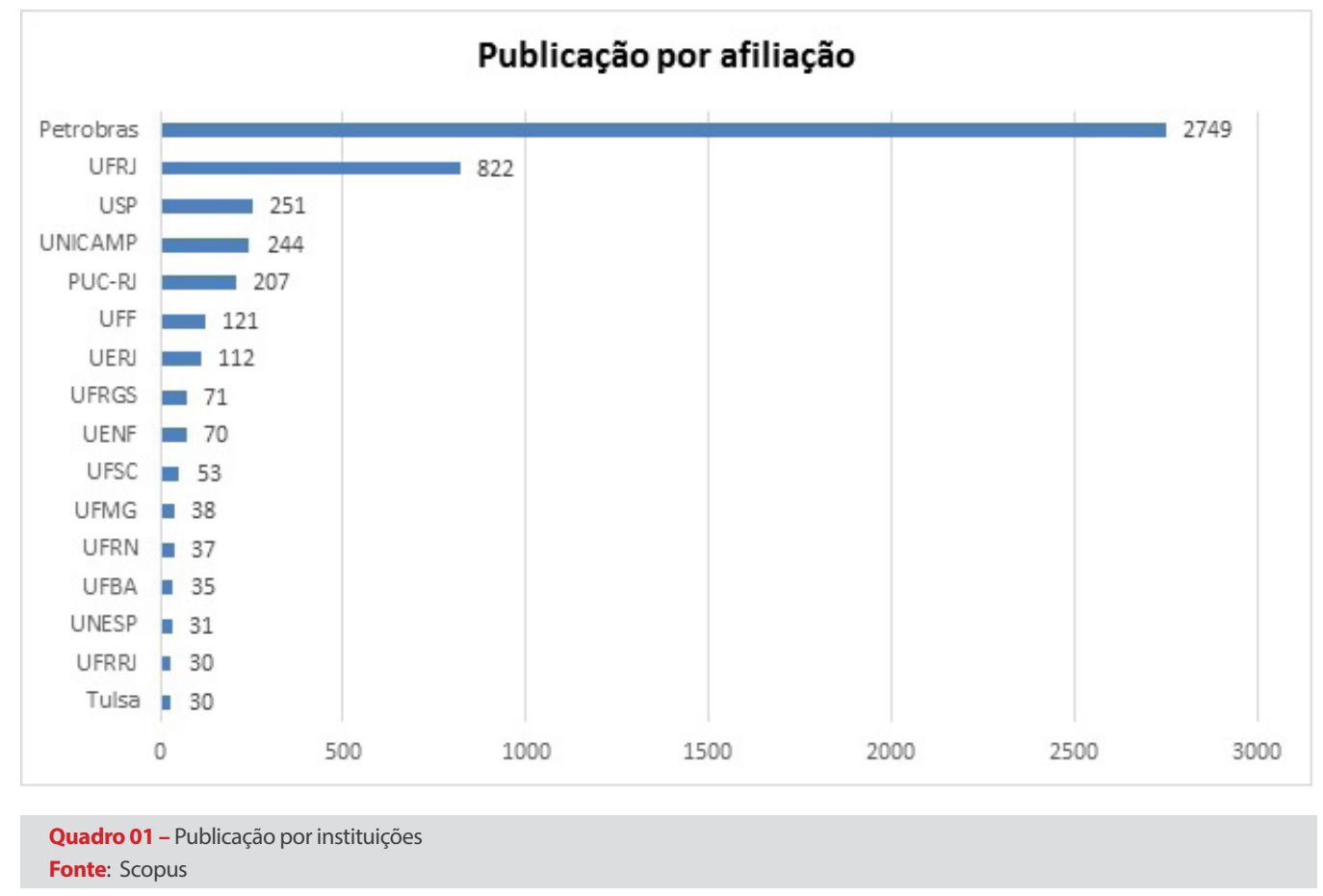

O crescimento da pesquisa, em números de publicação, começou em 1996, momento em que o país reelaborou suas estratégias de desenvolvimento, com a Lei 9.279, que entrou em vigor em 15 de maio de 1997 e passou a orientar as decisões sobre a propriedade industrial no Brasil. Em 2002 ocorreu um novo crescimento, e o ano de 2010 despontou como o de maior produção de documentos (Quadro 2), 443 no total, coincidindo com a ampliação das instalações do CENPES, já mencionada no presente trabalho como um referencial do aumento das atividades de P\&D da empresa, cuja capitalização em 2010 foi de US\$72,8 bilhões, atingindo o valor de mercado de US $\$ 220$ bilhões.

O quadro a seguir (Quadro 2) apresenta dados da produção científica anual, em pesquisa realizada na base Scopus, utilizando o termo Petrobras, no campo Affiliation name. 
Publicação por ano

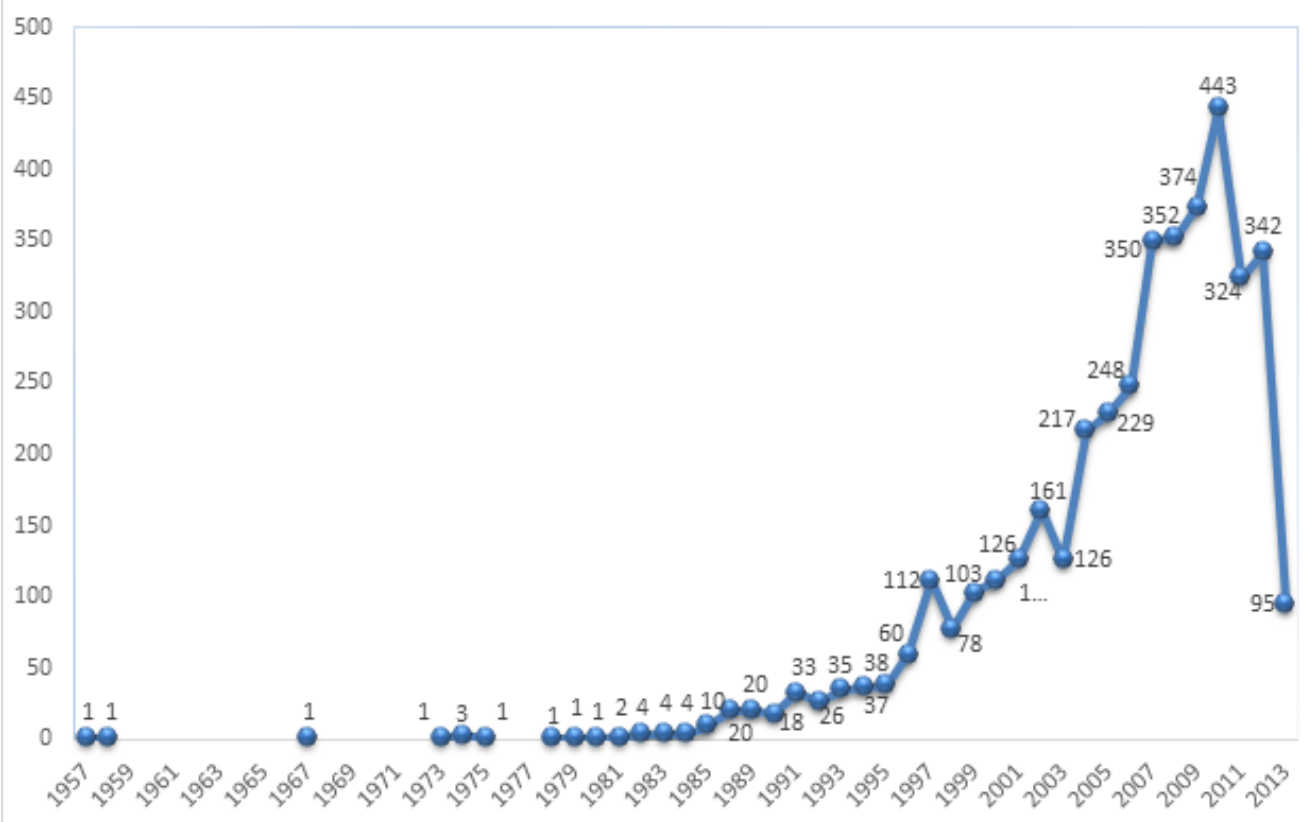

Quadro 02 - produção científica anual da Petrobras.

Fonte: Scopus

O autor de maior índice de produtividade na amostra possui título de Doutor em Engenharia Química pela UFRJ e tem vínculo institucional de Consultor Sênior na Petrobras, segundo descrição no Currículo Lattes em 2013. De acordo com Diretório de Grupos de Pesquisa no Brasil do CNPq, atuava em dois grupos, um de Geomecânica do Petróleo da PUC-Rio, e o outro de Macromoléculas e Colóides na Indústria de Petróleo da UFRJ, classificado com área predominante em Ciências Exatas e da Terra; Química. É interessante notar que o autor que aparece em segundo lugar de produtividade de documentos, é líder do grupo Macromoléculas e Colóides na Indústria de Petróleo da UFRJ, demonstrando uma rede de relacionamento produtiva para ambos os pesquisadores.

O quadro a seguir (Quadro 3) apresenta dados da produção científica por autor, em pesquisa realizada na base Scopus, utilizando o termo Petrobras, no campo Affiliation name. 


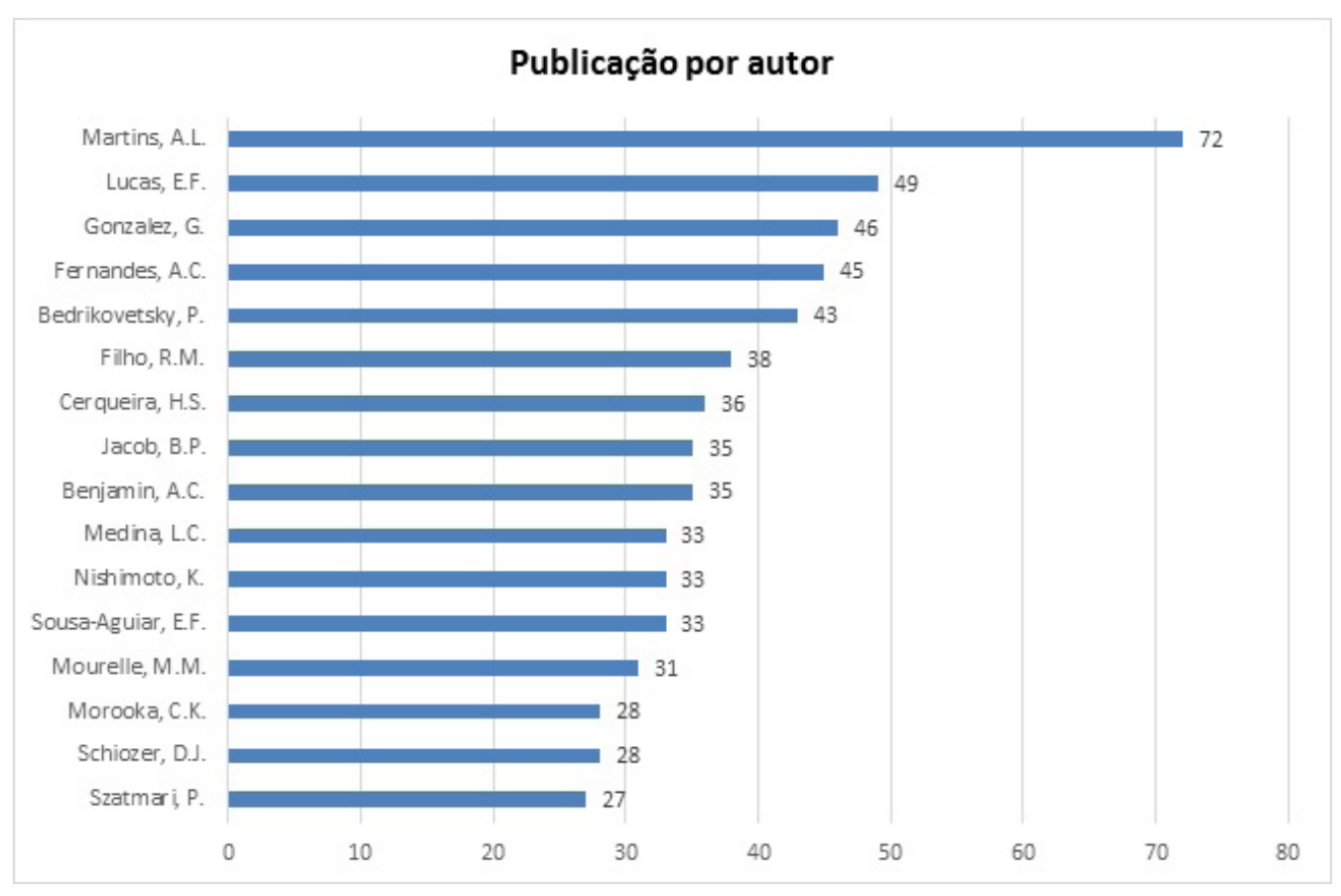

Quadro 03 - produção científica por autor.

Fonte: Scopus

Mais de 50\% dos documentos recuperados na pesquisa são publicações em Conferências, e 44,9\% são artigos científicos (Quadro 4). As áreas predominantes dos temas de pesquisa são a Engenharia com 1530 documentos, Ciências da Terra com 1227, seguida por Energia com 1093 e Engenharia Química com 948, e Química com 437 documentos (Quadro 5). Vale lembrar que no caso da UFRJ as áreas de Engenharia, Energia, Engenharia Química pertencem ao Centro de Tecnologia, e que a Química tanto pode estar presente no Instituto de Química, que pertence ao Centro de Ciências Matemáticas e da Natureza, quanto na Escola de Engenharia Química ou Instituto de Macromoléculas, o mesmo valendo para Ciências dos Materiais, que tanto pode estar no Instituto de Química, na Escola de Engenharia Química, no Instituto de Macromoléculas, ou na Engenharia Metalúrgica e de Materiais. Portanto, os dados apresentados respaldam com o que dizem Kannebley e Carolo (2013, p. 103) "O efeito positivo da interação com o CTPETRO é concentrado no incremento da produção de artigos na área de Engenharia”.

O quadro a seguir (Quadro 4) apresenta dados da produção científica por tipo de documento em pesquisa realizada na base Scopus, utilizando o termo Petrobras, no campo Affiliation name. 


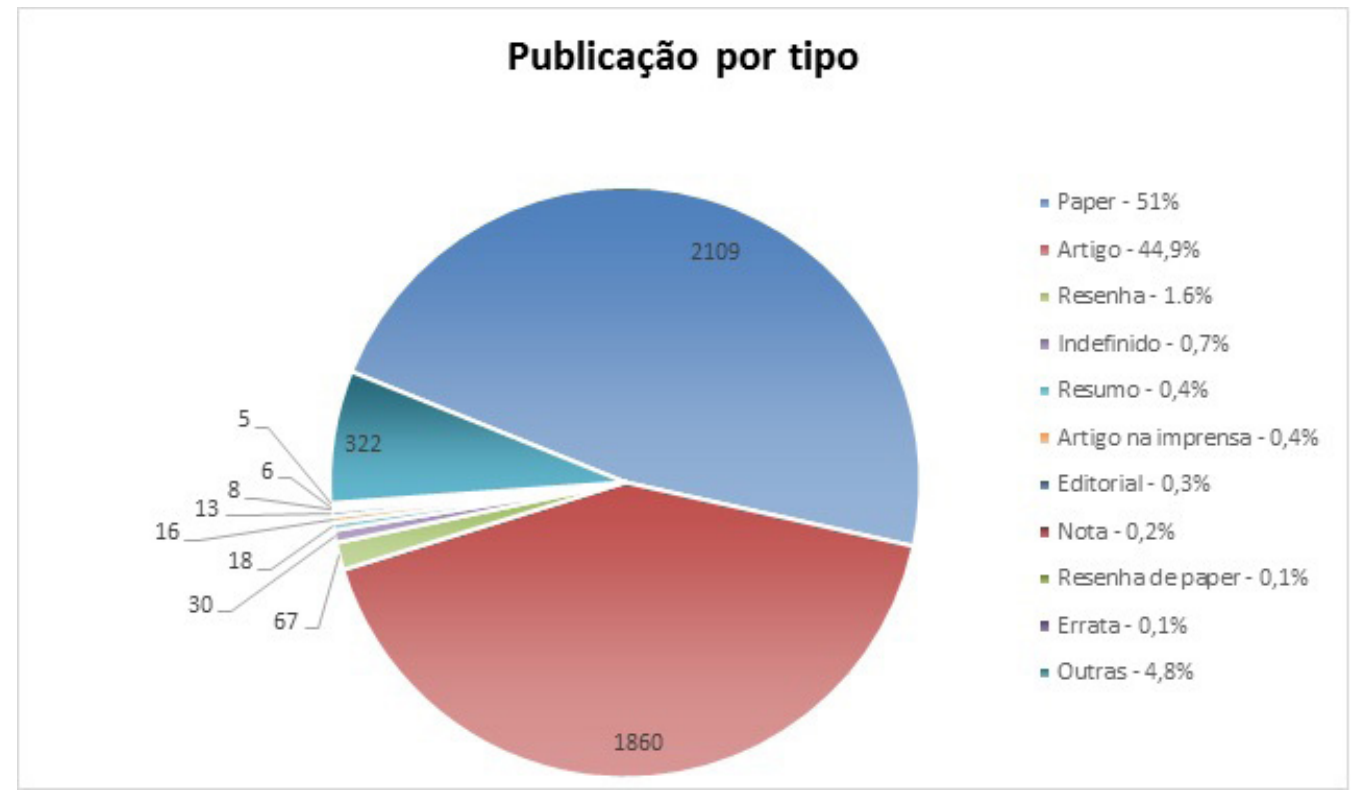

Quadro 04 - produção científica por tipo de documento.

Fonte: Scopus

O quadro a seguir (Quadro 5) apresenta dados da produção científica por área do conhecimento em pesquisa realizada na base Scopus, utilizando o termo Petrobras, no campo Affiliation name.

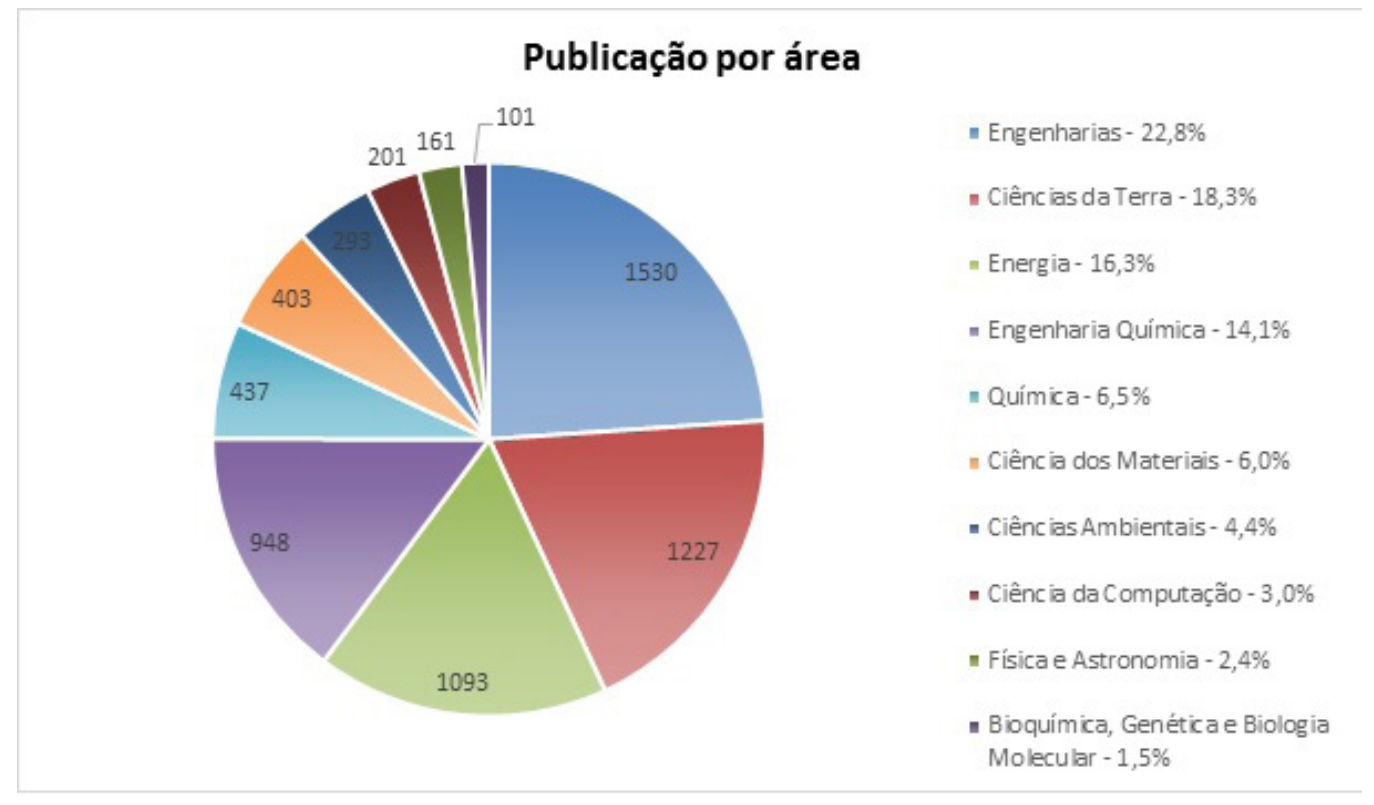

Quadro 05 - produção científica por área do conhecimento.

Fonte: Scopus

A publicação que apresenta o maior número de artigos de autores afiliados a Petrobras, é: Proceedings of the International Conference on Offshore Mechanics and Arctic Engineering (OMAE), evento promovido anualmente pela American Society of 
Mechanical Engineers (ASME) sediada nos Estados Unidos.

Como é possível notar trata-se de publicação de uma conferência internacional em que o tema central é a discussão sobre o mar. Este dado corrobora o discurso de Graça Foster, presidente da Petrobras, no Seminário "Investimento em Infraestrutura: Base do Desenvolvimento", promovido pela Revista Brasileiros, em junho 2013, no qual destaca que até 2020, a produção de petróleo passará dos atuais 2 milhões de barris por dia para 4,2 milhões, beneficiando-se da recuperação da indústria naval, responsável pela construção de sondas e barcos de apoio. "Para alcançar essa produção de petróleo e cumprir os níveis de conteúdo local, nós tivemos o privilégio de fazer renascer a indústria naval offshore no Brasil", afirmou Graça Foster, segundo notícias publicadas no site da empresa (PETROBRAS, 2013, online).

O quadro a seguir (Quadro 6) apresenta dados referentes a produção de artigos por título das publicações, em pesquisa realizada na base Scopus, utilizando o termo Petrobras, no campo Affiliation name.

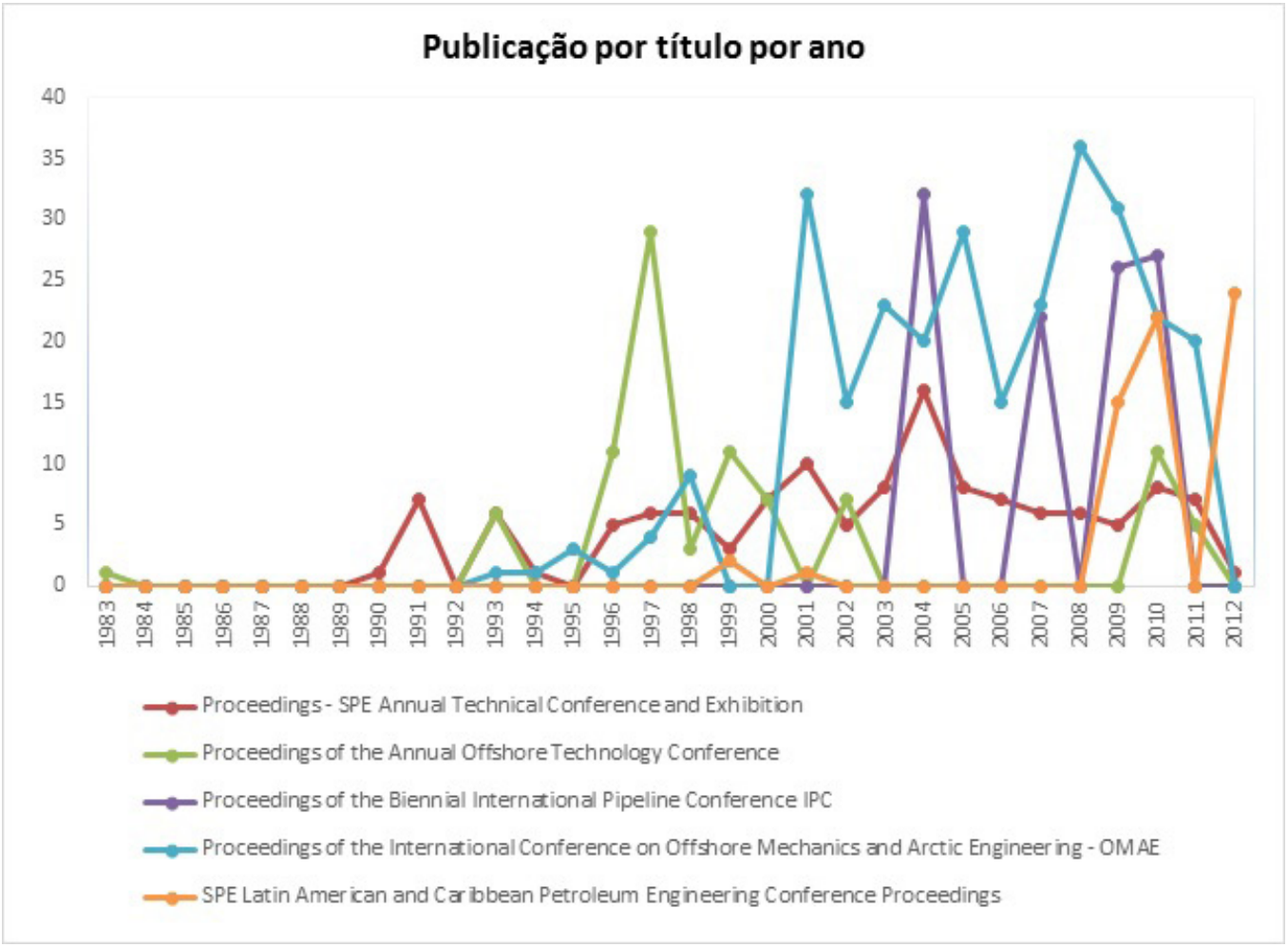

Quadro 06 - produção científica por título de documento.

Fonte: Scopus

\subsection{Base Minerva}

Na Base Minerva, para estabelecer as categorias de análise, os parâmetros da pesquisa foram: Base de Teses e Dissertações, busca na opção Todos os Campos o termo Petrobras, permitindo localizar o termo solicitado tanto nos resumos dos trabalhos, quanto nos assuntos foram autoria e título; o resultado obtido foi de 190 registros, no período de 1968 (primeiro registro disponíveis retornado) até 2013, sendo dividido entre 160 dissertações de Mestrado, e 30 teses de doutorado. A área com maior produção de teses 
ou dissertações relacionadas com o termo Petrobras, é a de Engenharia Oceânica. Vale destacar que teses e dissertações que envolvem registro de patentes não são divulgadas por um período de um ano, podendo ser renovado, e podem não ter constado no levantamento.

O quadro a seguir (Quadro 7) apresenta dados referentes a produção anual de teses e dissertações da UFRJ, a partir do termo Petrobras na Base Minerva.

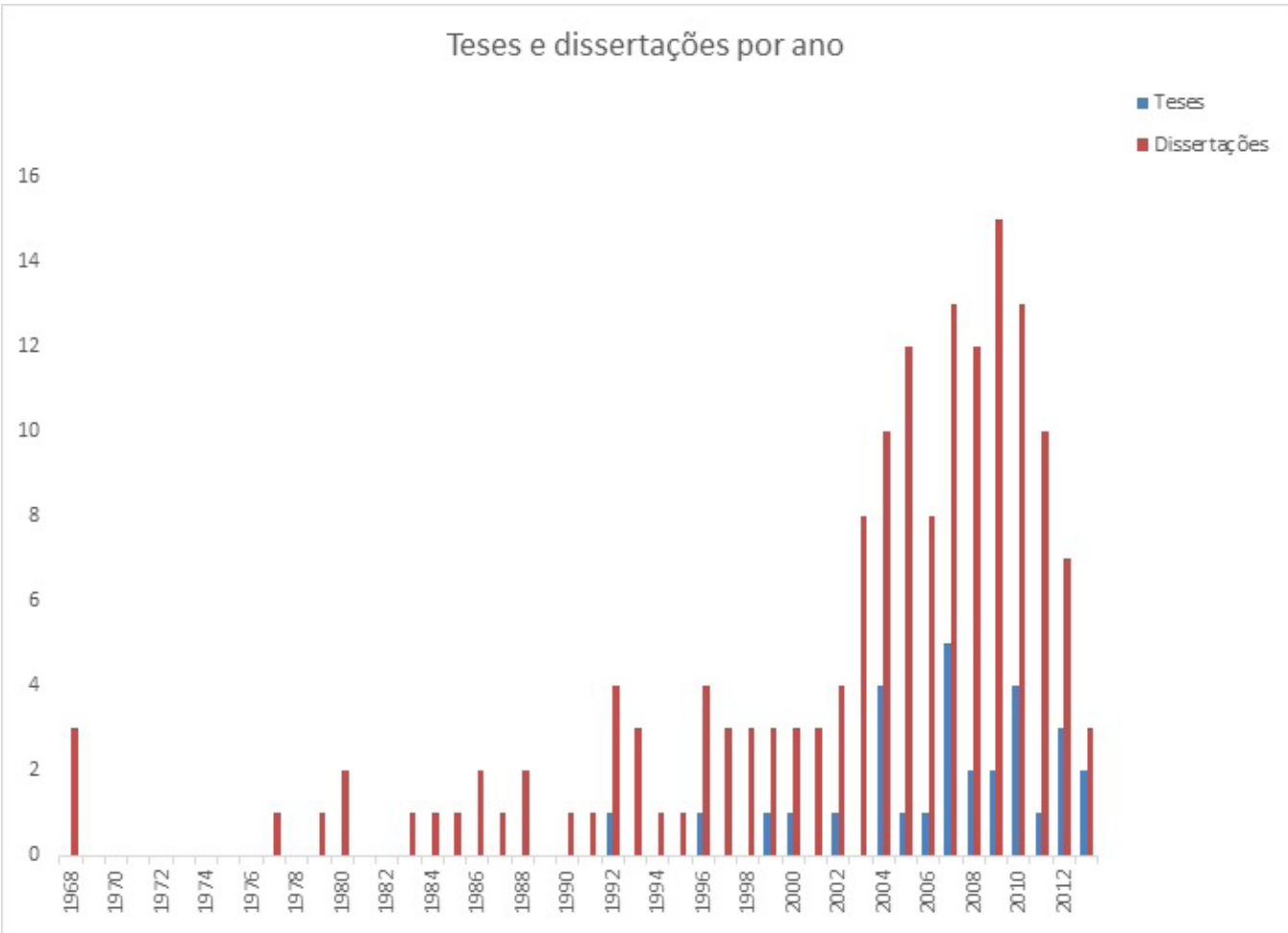

Quadro 07 - Produção anual de Teses e Dissertações da UFRJ.

Fonte: Base Minerva.

O quadro a seguir (Quadro 8) apresenta dados referentes a produção por área de teses e dissertações da UFRJ, a partir do termo Petrobras na Base Minerva.

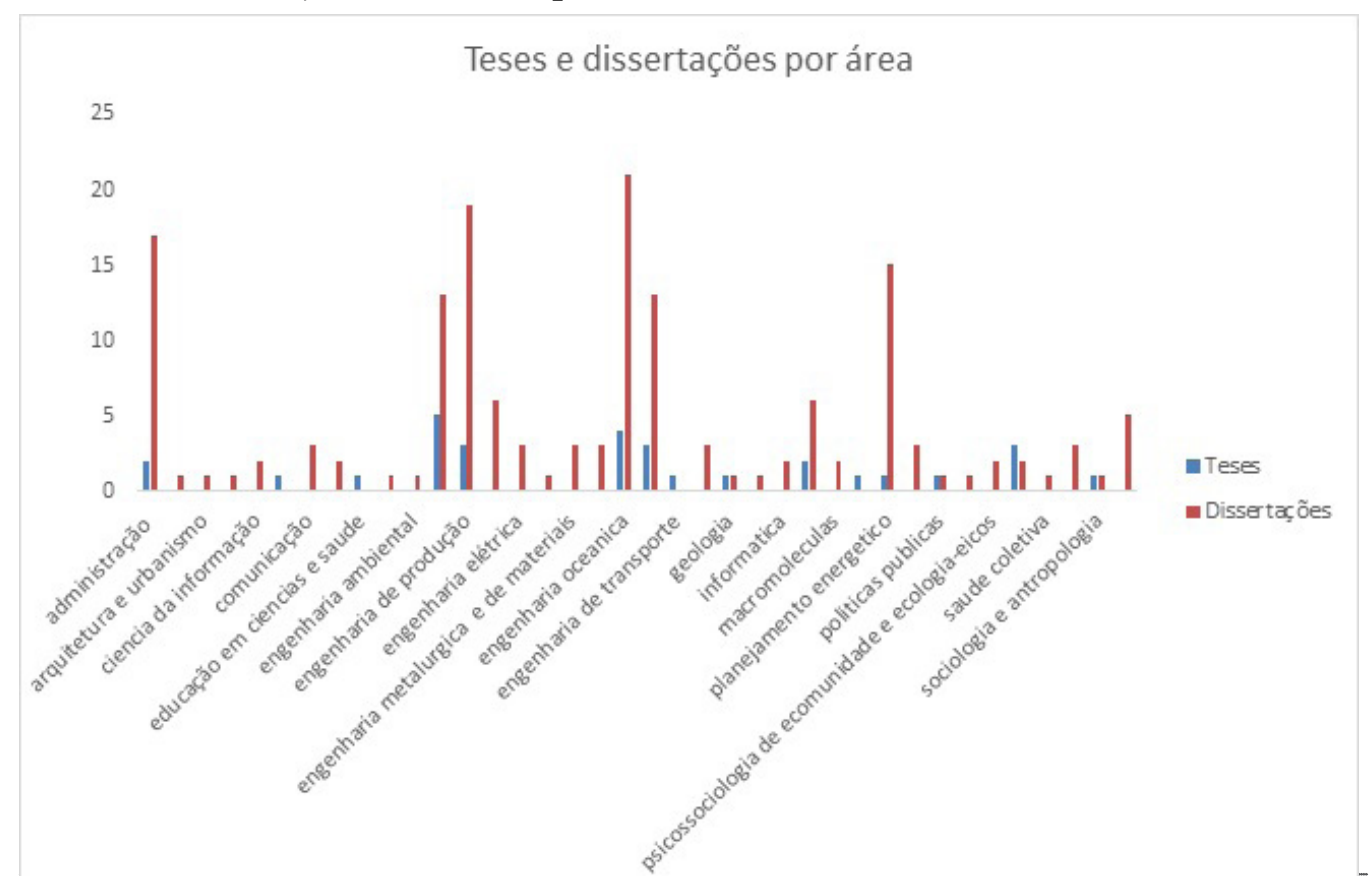




\subsection{Instituto Nacional da Propriedade Industrial (INPI)}

Na base do INPI, para estabelecer as categorias de análise, o parâmetro da pesquisa foi no campo nome do depositante: Petrobras, onde foram recuperados 1345 solicitações de pedidos de patentes no INPI. Como a base do INPI não oferecia a possibilidade de cruzamentos de dados, optou-se primeiramente em utilizar o termo da UFRJ por extenso em nome do depositante: Universidade Federal do Rio de Janeiro o que apresentou um total de 340 solicitações de pedidos de patentes no INPI. Já o nome do depositante: UFRJ apresenta 241 solicitações de pedidos de patentes, testando o termo nome do depositante: COPPE recuperou-se 70 solicitações de pedidos de patente. Diante da diversidade dos números e das Unidades da UFRJ, os campos de busca foram alterados para depositante: Petrobras, Resumo: Universidade Federal do Rio de Janeiro, o que totalizou 972 solicitações de pedidos de patentes.

O primeiro pedido de patente encaminhado pela Petrobras ao INPI, feito em 1955, não foi de nenhuma tecnologia de exploração, produção ou refino de petróleo, e sim de uma marmita térmica. Segundo Ávila (2006, p. 44) "essa iniciativa simples partiu da motivação pela busca de melhorias e da observação atenta do cotidiano, o mesmo mecanismo de inovação adotado há milhares de anos". Daqueles dias até hoje, a área de petróleo é predominante e a Petrobras já conta com 1345 processos de pedidos de patentes no INPI.

A interação entre empresa, universidade, e governo, representa um processo essencial para cada um deles, considerando o conhecimento como elemento indispensável da cadeia produtiva entre ciência e tecnologia. A patente como fonte de informação permite estabelecer vantagens, uma vez que a informação pode se constituir em fonte e ser usada na produção de novo conhecimento, gerando novas fontes de informação e ampliando as possibilidades de geração novas competências.

Segundo Garcia (2006, online):

A Lei de Inovação pretende estimular parcerias entre empresas, universidades, institutos de pesquisa e governo federal, objetivando a inovação tecnológica e a ampliação do parque tecnológico brasileiro. Declarada a necessidade de mudar a realidade que destaca a desburocratização da relação entre setor público e setor privado; facilidade na transferência de tecnologia, utilização de recursos humanos e de infraestrutura das instituições de pesquisa e a remuneração do pesquisador envolvido nos projetos de parceria.

\section{Considerações finais}


Este trabalho procurou refletir sobre como a gestão da informação pode auxiliar no planejamento estratégico da biblioteca universitária, no caso utilizando a ferramenta de análise de impacto para identificar a representação da Petrobras na UFRJ. Foi possível observar nas análises que a retomada da política industrial brasileira, e os investimentos do governo nas atividades de C\&T contribuíram para o fortalecimento de pesquisas em diversas áreas. O crescimento da pesquisa na Petrobras, em números de publicação, começou em 1996, passando de 38 documentos em 1995 para 60 documentos no ano seguinte. Em 2002 ocorreu um novo crescimento, e o ano de 2010 despontou como o de maior produção de documentos, coincidindo com as novas estratégias de desenvolvimento adotadas no país. Indicam também que os investimentos em pesquisas e os resultados estão atrelados à conjuntura político-econômica. Neste caso específico sofrendo influência do mercado internacional do petróleo, que entrou em declínio em 2013, e dos problemas enfrentados pela Petrobras com corrupção, no mesmo período, além da crise econômica que se instalou no país, levando ao declínio da produção.

Os dois primeiros pesquisadores que despontam no levantamento de artigos publicados, participam do mesmo grupo de pesquisa: Macromoléculas e Colóides na Indústria de Petróleo da UFRJ, o primeiro autor é consultor sênior da Petrobras, e o segundo autor é a líder do grupo. A participação em eventos da área representa a maioria das publicações da empresa e a área predominante dos temas de pesquisa é a Engenharia. A publicação com maior número de artigos de autores afiliados a Petrobras, é: Proceedings of the International Conference on Offshore Mechanics and Arctic Engineering, publicação de evento internacional em que o tema central é a discussão sobre o mar. Estes dados equiparam-se a produção de teses e dissertações da UFRJ, a partir da pesquisa pelo termo Petrobras na Base Minerva, em que o curso que aparece com maior produção é o de Engenharia Oceânica.

Enfim, foi possível observar que os resultados das pesquisas se encontram em diferentes fases, de acordo com as áreas de interesse de desenvolvimento científico para o país. Como dizem Kannebley e Carolo (2013, p. 107):

\footnotetext{
Uma possível explicação para resultados distintos entre grandes áreas do conhecimento encontra-se nos diferentes estágios de desenvolvimento das ciências no Brasil, bem como da dependência dessas áreas para com os recursos de pesquisa transferidos pela Petrobras. O impacto é positivo principalmente na área de Engenharia que é mais fortemente influenciada pela Petrobras, seja pela dependência de oferta de recursos, ou ainda pela importância de sua temática de pesquisa. Ademais, a área de Engenharia é relativamente recente no Brasil.
}

O exemplo utilizado mostra que os dados obtidos podem ajudar os planejadores a identificar lacunas de conteúdo informacional, parcerias que devem incrementadas ou estimuladas e a necessidade de novos serviços para atender às necessidades de conhecimento dos usuários.

Este trabalho buscou contribuir para a apresentação de iniciativas dos profissionais bibliotecários em um debate inevitável na universidade sobre a participação da instituição no desenvolvimento do país, bem como seu comportamento diante das parcerias proporcionadas pelas empresas instaladas no Parque Tecnológico da Cidade Universitária na Ilha do Fundão ou ainda outras instituições, sejam elas externas à 
universidade ou interdepartamentais, na produção do conhecimento científico. Os bibliotecários possuem a expertise do acesso às bases de dados, que vão além dos treinamentos às bases de dados, dominam as técnicas de uso das ferramentas disponíveis no Portal Capes e desenvolvem habilidades que lhes respaldam a desenvolver produtos e análises da informação que possam contribuir no processo de tomada de decisão.

\section{REFERÊNCIAS}

AMARAL, Roniberto Morato do et al. Sistemática para o planejamento estratégico de bibliotecas: caso Biblioteca Comunitária da UFSCAR. In: XXIII CONGRESSO BRASILEIRO DE BIBLIOTECONOMIA E DOCUMENTAÇÃO, 2009, Bonito. Anais... Bonito: UFMS, 2009.

ANSOFF, H. Igor; MCDONNELL, Edward J. Implantando a administração estratégica. São Paulo: Atlas, 1993.

ÁVILA, Jorge de Paula Costa. Desenvolvimento, inovação e propriedade intelectual no Brasil. In: BRASIL. Ministério do Desenvolvimento Indústria e Comércio Exterior. Instituto Nacional de Propriedade Industrial. A história da tecnologia brasileira contada por patentes. Rio de Janeiro: INPI, 2008.

BRASIL. FINEP. O que são os fundos. Rio de Janeiro, 2012. Disponível em <http://www.finep.gov.br/pagina.asp?pa$\mathrm{g}=$ fundos o que sao $>$. Acesso em: 13 jul. 2013.

BRASIL. Ministério do Desenvolvimento Indústria e Comércio Exterior. Instituto Nacional de Propriedade Industrial. A história da tecnologia brasileira contada por patentes. Rio de Janeiro: INPI, 2008.

jul. 2013

Portal da inovação. Disponível em <http://www.portaldainovacao.org/inpi/sobre>. Acesso em: 13

COCHRANE, Pauline A. information technology in libraries and Ranganathan's five laws of library science. Libri, v. 42, n. 3, p. 235-241, jun. 1992.

DELAIA, C. R.; FREIRE, I. M. Subsídios para uma política de gestão da informação da Embrapa Solos: à luz do regime de informação. Perspectivas em Ciência da Informação, v. 15, n. 3, p. .107-130, set./dez. 2010.

DI FOGGI, Rafael Antônio; COLETTA, Teresinha das Graças; CRISTIANINI, Glaucia Maria Saia. Planejamento estratégico em bibliotecas universitárias estaduais públicas do estado de São Paulo: análise, avaliação e proposta de um roteiro. In: SEMINÁRIO INTERNACIONAL DE BIBLIOTECAS DIGITAIS, 2010. Rio de Janeiro. Anais... Rio de Janeiro: UFRJ, 2010.

GARCIA, Joana Coeli Ribeiro. Os paradoxos da patente. DataGramaZero, Rio de Janeiro, v. 7, n. 5, 2006. Disponível em: <http://www.dgz.org.br/out06/Art_04.htm>. Acesso em: 13 jul. 2013.

KANNEBLEY JÚNIOR, Sérgio; CAROLO, Murilo Damião. O impacto da interação universidade empresa na produtividade dos pesquisadores: uma análise dos docentes coordenadores de projetos com apoio da PETROBRAS/ANP. In: INSTITUTO DE PESQUISA ECONÔMICA APLICADA. Impactos tecnológicos das parcerias da Petrobras com universidades, centros de pesquisa e firmas brasileiras. Brasília: Ipea: Petrobras, 2013. p. 81-114p.

LONGO, Rose. A importância do conhecimento e do profissional da informação para uma estratégia corporativa num contexto de complexidade. In: SOUTO, Leonardo Fernandes (Org.). Gestão da informação e do conhecimento: práticas e reflexões. Rio de Janeiro: Interciência, 2014.

MAIA, Maria Eugênia; OLIVEIRA, Bernardina Maria Juvenal Freire de. Planejamento Estratégico para o Sistema Integrado de Bibliotecas como elemento de ação empreendedora. In: XV SEMINÁRIO NACIONAL DE BIBLIOTECAS UNIVERSITÁRIAS, 2008. Anais... São Paulo: Unicamp, 2008.

MINTZBERG, Henry; QUINN, James Brian. O processo de estratégia. Porto Alegre: Bookman, 2001. 
MUGNAINI, Rogério; STREHL, Letícia. Recuperação e impacto da produção científica na era do Google: uma análise comparativa entre o Google Acadêmico e a Web of Science. Revista Eletrônica de Biblioteconomia e Ciência da Informação, Florianópolis, n. esp., p. 92-105, jan./jun. 2008.

PEREIRA, A.G.; CIANCONI, R.B. Potencial de atuação do bibliotecário em atividades de inteligência organizacional: estudo de caso na Universidade Federal Fluminense. Transinformação, Campinas, v. 20, n. 1, 2008. Disponível em: <http://periodicos.puc-campinas.edu.br/seer/index.php/transinfo/article/view/543>. Acesso em: 25 jul. 2013.

PETROBRAS. Petrobras e UFRJ inauguram núcleo de biocombustíveis, de petróleo e de seus derivados. Rio de Janeiro, 2013. Disponível em: <http://fatosedados.blogspetrobras.com.br/2012/07/06>. Acesso em: 25 jul. 2013.

Notícias. Rio de Janeiro, 2013. Disponível em: <http://www.petrobras.com.br/pt/noticias $>$. Acesso em: 25 jul. 2013

PRADO, Eleutério F. S. Mercado na universidade. Jornal da USP, n. 508, p. 5-6, 2000

UNIVERSIDADE FEDERAL DO RIO DE JANEIRO. Agência UFRJ de Inovação. Sobre a Agência. Disponível em <http://www.inovacao.ufrj.br/index.php/a-agencia/sobre-agencia >. Acesso em: 25 jul. 2013.

VOGT, Carlos. O petróleo é nosso. Energia, São Paulo, v. 7, n. 5, 2011. Disponível em <http://www.univesp.ensinosuperior.sp.gov.br/preunivesp/963>. Acesso em: 13 jul. 2013. 